\title{
INTERVENCIÓN DE MARCIA COVARRUBIAS, EMBAJADORA DE CHILE EN FRANCIA
}

Estamos reunidos aquí para celebrar y cumplir un deber de reconocimiento y gratitud de mi país con el profesor y gran amigo de Chile, el profesor Patrice Vermeren.

En efecto, nuestro país tiene una deuda inmensa y permanente de recuerdo y reconocimiento por la solidaridad que hemos recibido en momentos de profundo sufrimiento.

En esa atmósfera de violencia sicológica, física, ante las intenciones de irrumpir de un sistema totalitario de pensamiento, resumido en una frase que me quedó grabada en la memoria, la expresó uno de vuestros amigos aquí presentes que viajó desde Chile. "Lo que veo con más claridad es una gran oscuridad" se titulaba una entrevista a Marcos García de la Huerta, de ese período negro de desesperanza; en medio del desconcierto y desasimiento de nuestra alma, llegó un fulgor y algunas luces de esperanza. Entre estos productores de luz, en lugar de honor, es preciso situar la contribución de Patrice Vermeren. Una idea de la profundidad de las tinieblas en las que fuerzas oscuras quisieron hundir a Chile puede darla el haber procedido a quemas de libros, incluidos los de la casa de Neruda.

Cómo no celebrar la aparición, entonces, en la escena filosófica, la más emblemática de la resistencia -la del pensamiento-, de una presencia con la eficacia de Patrice Vermeren. En él reconocemos esta magnífica red que ustedes crearon juntos a partir de 1984-1985, los filósofos chilenos (excluidos o marginados al comienzo de su universidad por la dictadura) y los filósofos franceses del College International de Philosophie, de la Universidad de Paris 8 y del Centro de Investigaciones de la Sorbona. Lo que comenzó con el CERC de la Academia de Humanismo Cristiano, y el primer coloquio franco-chileno de filosofía en Santiago en 1986, con Rodrigo Alvayay, Carlos Ruiz Schneider, Humberto Giannini, Marcos García de la Huerta, Patricio Marchant, Cecilia Sánchez, María Teresa P., Carlos Contreras, Pablo Oyarzún, Poupin, Pedro Miras, Patricia Bonzi, Cristina Hurtado, José Jara, Claudia Gutiérrez, Renato Cristi, Carlos Ossandón, Justo Mellado, Guadalupe Santa Cruz, Sol Serrano, Cristián Gazmuri, Olga Grau, Rafael Parada, Willy Thayer, Alejandro Madrid, Iván Trujillo, Miguel Vicuña, Ricardo Salas, María Emilia Tijoux, etc., con la complicidad activa de Enrique d'Etigny y la Embajada de Francia, fue seguido por un intenso intercambio de profesores y estudiantes, y gestiones mayores con la Embajada de Francia como "un avión de libros para Chile”. Este apoyo nunca desfalleció, pues tan pronto recuperada la democracia tuvo lugar el coloquio sobre "Spinoza y la democracia".

Luego vinieron cursos, coloquios, conferencias y relaciones intensas con numerosas universidades: Universidad de Chile, de Valparaíso, de Santiago, PUC 
Valparaíso, Diego Portales, Andrés Bello, Academia de Humanismo Cristiano, Playa Ancha, Concepción y Temuco, Austral de Puerto Montt, etc. Varios programas ECOS franco-chilenos; todo este conjunto de actividades e intercambios académicos condujo a la constitución de una cátedra Unesco de filosofía, la primera en el mundo, que ha permitido regionalizar estos intercambios filosóficos, que abarcarán en adelante a todos los países del cono sur y otros. Y hasta hoy numerosas cotutelas de tesis de doctorado, estadías de profesores invitados, que dan a esta escena filosófica franco-chilena una dimensión euro-latinoamericana.

Este progreso ha sido posible gracias a la perseverancia, la paciencia, la pasión y el amor de Patrice Vermeren por nuestro país. Es por eso que la Ministra de Educación, en nombre del Gobierno de Chile, ha resuelto, en ejercicio de sus facultades, condecorar a usted con la Orden Gabriela Mistral en el grado de Comendador. Esta Orden que lleva el nombre de nuestra gran poetisa, primer Premio Nobel de Literatura de Chile en 1945, Cónsul vitalicio de Chile, viene a coronar los esfuerzos en el ámbito de la educación, la cultura y los intercambios como los realizados por Patrice Vermeren, profesor emérito del Departamento de Filosofía de la Universidad de Paris 8. 